\title{
Ethnic differences in bone health
}

\author{
Ayse Zengin ${ }^{1}$, Ann Prentice ${ }^{1,2}$ and Kate Anna Ward ${ }^{1}$ * \\ Medical Research Council Human Nutrition Research, Cambridge, UK \\ ${ }^{2}$ Medical Research Council, Keneba, Gambia
}

Edited by:

Jonathan H. Tobias, University of

Bristol, UK

\section{Reviewed by:}

Jennifer Tickner, University of

Western Australia, Australia

Mark H. Edwards, MRC Lifecourse

Epidemiology Unit, UK

*Correspondence:

Kate Anna Ward, MRC Human

Nutrition Research, Elsie Widdowson

Laboratory, Fulbourn Road,

Cambridge CB1 9NL, UK

e-mail: kate.ward@mrc-hnr.cam.ac.uk
There are differences in bone health between ethnic groups in both men and in women. Variations in body size and composition are likely to contribute to reported differences. Most studies report ethnic differences in areal bone mineral density (aBMD), which do not consistently parallel ethnic patterns in fracture rates. This suggests that other parameters beside aBMD should be considered when determining fracture risk between and within populations, including other aspects of bone strength: bone structure and microarchitecture, as well as muscle strength (mass, force generation, anatomy) and fat mass. We review what is known about differences in bone-densitometry-derived outcomes between ethnic groups and the extent to which they account for the differences in fracture risk. Studies are included that were published primarily between 1994 and 2014. A "one size fits all approach" should definitely not be used to understand better ethnic differences in fracture risk.

Keywords: ethnic groups, bone, muscle, pOCT, DXA, fracture, skeletal, bone mineral density

\section{INTRODUCTION}

There are differences in fracture risk between ethnic groups in both men and in women across the globe. It is important to understand the underlying phenotype that contributes to these differences in order to be able to determine strategies for the prevention of osteoporosis and bone fragility in an ever-changing environment. Most studies report ethnic differences in areal bone mineral density (aBMD), which do not consistently parallel ethnic patterns in fracture rates. Variations in body size and composition are likely to contribute to reported differences.

Traditionally, aBMD $\left(\mathrm{g} / \mathrm{cm}^{2}\right)$ measured by single and dual energy x-ray absorptiometry (DXA) or photon absorptiometry (SPA/DPA) is used as a surrogate for bone strength and fracture risk. DXA superseded SPA/DPA over 30 years ago. DXA has many advantages, including good precision, low radiation dose, and ability to scan skeletal sites most prone to osteoporotic fracture. Areal BMD predicts fracture and in Western White older adults, a 1SD decrease in aBMD leads to 2.6 -fold greater fracture risk (1). However, DXA only measures aBMD $\left(\mathrm{g} / \mathrm{cm}^{2}\right)$, projectional bone area $\left(\mathrm{cm}^{2}\right)$, and bone mineral content (BMC, $\mathrm{g}$ ) and as such does not fully account for bone size because it cannot account for differences in bone depth. Additionally, DXA is an average value across all bony elements within the periosteal envelope and so does not assess the separate compartments within bone (cortical or trabecular), bone structure (size and shape), organization within the periosteal envelope (e.g., cortical thickness), microarchitecture (e.g., trabecular thickness, number, cortical porosity), or bone metabolism, all of which are important components of bone strength. The aforementioned limitations are thought to be the basis for the inadequacies of aBMD in predicting fracture in different ethnic groups (2). The advancement of imaging technology to include central, peripheral, and high-resolution peripheral quantitative computed tomography (QCT, pQCT, and HRpQCT) has enabled the measurement of volumetric bone mineral density
(vBMD), the structural dimensions, and internal organization of cortical and trabecular bone and to give in vivo estimates of bone strength. With its greater spatial resolution $(82 \mu \mathrm{m})$, HRpQCT also measures trabecular and cortical microarchitecture; it measures trabecular number directly and provides indirect estimates of trabecular bone volume, trabecular thickness, trabecular separation, and bone strength (3).

Throughout this review, ethnicity has been used to group individuals according to a mix of cultural and other factors including geography, language, diet, religion, ancestry, and physical features traditionally associated with race. The glossary in Table $\mathbf{1}$ has summarized and defined each ethnic group that is discussed in this review.

This review focuses on evidence from studies using bonedensitometry techniques and those reporting fracture incidences. With the aforementioned technical developments and the recognition of the limitations of DXA, recent studies have focused on describing ethnic differences in bone structure and bone microarchitecture and the extent to which these may contribute to differences in fracture risk. However, as this review highlights, there are still relatively few data available outside of US, particularly in populations where fracture incidence is predicted to rise over the coming decades.

\section{FRACTURE INCIDENCE AND BMD ACROSS THE GLOBE}

Global data on adults suggest that, compared to age-matched White-American or British/European populations, other ethnic groups have a lower incidence of fracture (Figure 1). There is a $>10$-fold variation in age-standardized hip fracture risk across 63 countries and a notable divide between Western and Eastern populations (4-6). Most recently, Cauley et al. (5) showed greater variability in incidence and geographic pattern for clinical vertebral fractures than for hip fracture; it should be noted that for radiographically confirmed vertebral fractures the global pattern 
Table 1 | Classification of ethnic groups

\begin{tabular}{|c|c|}
\hline Ethnic group & Definition \\
\hline White-American & European ancestral origins living in US \\
\hline Black-American & African ancestral origins living in US \\
\hline Asian-American & $\begin{array}{l}\text { Collective group of eastern Asian (Japanese, } \\
\text { Chinese) ancestral origins living in US }\end{array}$ \\
\hline Chinese-American & Chinese ancestral origins living in US \\
\hline Japanese-American & Japanese ancestral origins living in US \\
\hline White-British & $\begin{array}{l}\text { English, Welsh, Scottish, and Northern Irish living } \\
\text { in UK }\end{array}$ \\
\hline South-Asian British & $\begin{array}{l}\text { Indian, Pakistani, and Bangladeshi ancestral roots } \\
\text { living in UK }\end{array}$ \\
\hline Afro-Caribbean British & $\begin{array}{l}\text { African ancestral origins whose forebears were in } \\
\text { the Caribbean before immigrating to UK }\end{array}$ \\
\hline Gambian & $\begin{array}{l}\text { Sub-Saharan African ancestral origins, primarily } \\
\text { Mandinka, living in The Gambia }\end{array}$ \\
\hline Gambian-British & $\begin{array}{l}\text { Sub-Saharan African ancestral origins, primarily } \\
\text { Mandinka, living in UK }\end{array}$ \\
\hline Chinese & Chinese ancestral origins living in China \\
\hline
\end{tabular}

incidence was similar to that for hip fracture (5). Globally, the lowest fracture rates are in populations with African ancestry (6), but there is a sparcity of data from the African continent, particularly Sub-Saharan Africa (5, 7, 8). In the late 1960s, Solomon et al. described differences between White and Bantu populations in adult fracture incidence to be similar to those reported in North-America between Black- and White-Americans (9). Data from Cameroon suggest similarities to populations from the developed world because women have higher incidence than men of low trauma fracture to the hip and wrist (10). Further data are required to confirm the generalizability of this observation. With a rising life expectancy, increasing "Westernization" of African populations, better survival for individuals with HIV, and increasing noncommunicable disease risk fracture incidence is also expected to rise and should be better characterized (5, 7, 10, 11). In Asian populations, a 15-fold increase in hip fracture incidences was reported in studies from Japan and Hong Kong $(12,13)$. Compared to Western populations, there also appear to be sex differences in the patterns of incidence where in China there were no sex differences and in Thailand, men have greater hip fracture incidence $(14,15)$.

To date, the majority of large population studies have used aBMD measured by DXA as a proxy for fracture risk to study ethnic differences in bone health. In men, data from the third National Health and Nutrition Examination Survey (NHANES III) showed that Black-Americans had a higher mean femoral neck and total hip aBMD compared to White-American men (16); these differences were similar to reported fracture rates between these ethnic groups (17). The osteoporotic fractures in men study (MrOS) used QCT and showed that Black-American and East Asian-American men had higher bone strength compared to White-American men due to greater vBMD at the femoral neck (18). Data from UKcohort of the European Male Aging Study (EMAS) compared White-British men to a group of Afro-Caribbean British and South-Asian British men. The Afro-Caribbean British group had higher aBMD at all sites compared to South-Asian British and White-British, both before and after adjustment for body size (19). However, vBMD of the distal radius assessed using pQCT was not different between the groups (20).

One of the largest multi-ethnic studies, the National Osteoporosis Risk Assessment (NORA) study (NORA) showed that Black-American women had higher, and Asian-Americans ${ }^{1}$ lower, aBMD in the study population (2). Even after adjusting for body weight and other risk factor covariates, the greater aBMD in BlackAmerican women persisted; however, Asian-American women had similar values to White-American women (2). Despite lower aBMD in Asian-American women, studies have shown lower rates of fracture compared to White-American women (2). In UK, South-Asian women had lower aBMD than White-British women before appropriate adjustment for body or bone size, thereafter there were no differences between groups $(21,22)$. Similarly, Chinese women had lower aBMD than White-British women; after adjustment for body size, these differences were attenuated (23). Furthermore, despite a lower size-adjusted BMC at the lumbar spine, hip, and radius in Gambian women compared to WhiteBritish women (independent of height and weight), there was a lower incidence of fracture among Gambian women (24), suggesting that there are other factors contributing to the lower fracture risk seen in Gambian women. Taken together, all of the studies discussed in this section suggest that there may be other components of bone strength that should be studied to help to better predict fracture risk in different populations.

\section{ETHNIC DIFFERENCES IN BONE STRUCTURE}

Earlier studies of bone structure show differences in body-segment proportions (sitting and standing height) and also in cortical parameters measured using histomorphometry, which may contribute to ethnic differences in fracture rates $(25,26)$. The most recent studies also demonstrate that bone structure and microarchitecture are different in ethnic groups and these variations are likely to contribute to the ethnic differences in fracture rates.

\section{DUAL ENERGY X-RAY ABSORPTIOMETRY}

The Study of Womens Health Across the Nation (SWAN) study reported no differences in aBMD between Chinese-American, Japanese-American, and White-American women, but bone structure varied greatly (27). Femoral neck cross-sectional area (total bone surface in a cross-section, exclusive of soft tissue spaces and pores) and section modulus of the hip, measured by DXA, were higher in Japanese-American compared to White-American women (27). A greater section modulus in Japanese-American women would give better resistance to axial compressive and bending stresses. In the previously described studies of Gambian and Chinese women, compared to White-British women, ethnic differences in hip axis length (HAL) have been reported, in addition to

\footnotetext{
${ }^{1}$ Residing in US, i.e., predominantly East Asian population
} 


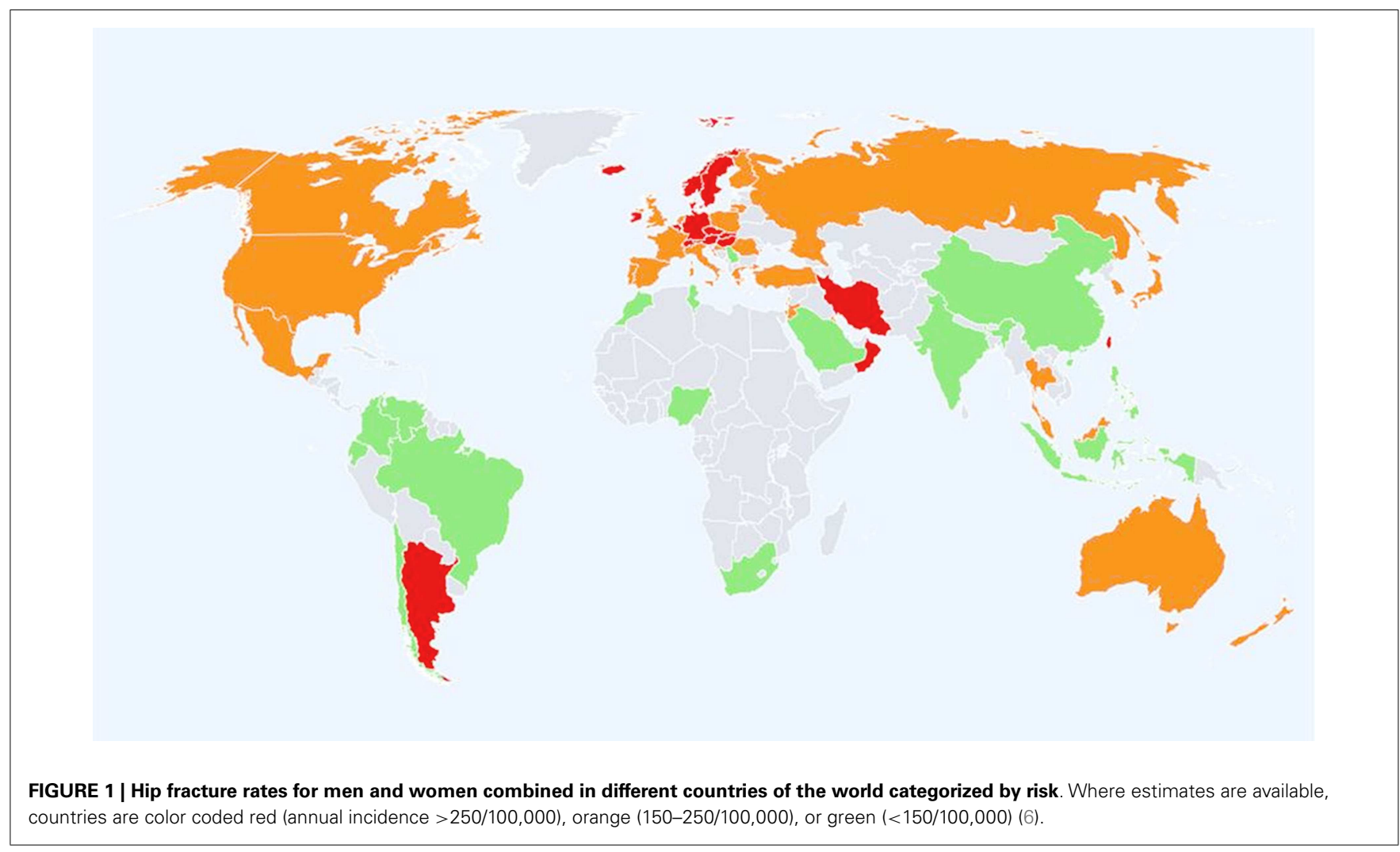

the aBMD differences $(23,28,29)$. Of the three groups, Gambian women had the shortest HAL after correction for height. Similarly, in a study in British men, HAL was shorter in Afro-Caribbean British men compared to White-British and South-Asian British men (19); similar results were reported in Gambian-British compared to White-British men after correcting for weight and height (28). A longer HAL has been associated with a higher risk of hip fracture, and is considered to be a risk predictor for hip fracture (30). And so, it is likely that these structural differences, in part, explain differences between ethnic groups of hip fracture incidence $(28,31)$.

\section{QUANTITATIVE COMPUTED TOMOGRAPHY}

In UK, there are only sparse data on bone structure measured by axial or peripheral QCT. Pre-menopausal South-Asian British women had lower cortical vBMD, BMC, and thinner cortices at the radial diaphysis compared to White-British women; this was independent of age, height, and weight (32). Despite lower BMC in the South-Asian British women, bone strength, as estimated using the strength strain index (SSI) was similar. This suggests that bones of pre-menopausal South-Asian British women may be efficiently adapted to a lower BMC as a result of a different distribution of bone mineral within the periosteal envelope, thereby preserving bone strength $(32,33)$. In contrast, another study has shown that post-menopausal South-Asian British women have lower SSI and fracture load at the radius and tibia despite having thicker cortices and higher vBMD; bone cross-sectional area was smaller (34).

In MrOS, Black-American and Asian-American men had thicker cortices, measured using axial QCT, than
White-Americans, which led to greater bone strength at the hip (18). Similarly, greater estimated bone strength was found in Afro-Caribbean British and South-Asian British men compared to White-British men. Lower strength in the White-British men was due to smaller bone size at the mid-shaft radius (20).

\section{HIGH-RESOLUTION pOCT}

Due to the relatively recent introduction of HRpQCT, there are only limited data using this technology. In a comparison of premenopausal women from US, Chinese-American women were shown to have smaller bones, with higher cortical vBMD and different trabecular microarchitecture than White-American women $(35,36)$. They appeared to have a structural advantage in their trabecular microarchitecture compared to White-American women, with larger, more plate-like trabecule, and a greater plate-rod junction density, which indicates the number of trabecular network connections (35). As plate-like structure contributes to a greater proportion of bone strength than the rods, these structural differences may explain the lower fracture risk in this group of women. Currently, there are no other data using HRpQCT to compare differences in bone structure. Lower fracture risk in African-American women is likely due to thicker cortices and better trabecular microarchitecture, both of which would be reflected in higher aBMD (a composite measurement of trabecular and cortical bone) previously reported in this ethnic group (37).

\section{ETHNIC DIFFERENCES IN BODY COMPOSITION}

There are major differences in body habitus (fat mass, muscle mass, height, and weight) between ethnic groups (Table 2), 
Table 2 | Ethnic differences in body composition in women and men.

\begin{tabular}{|c|c|c|c|c|c|c|c|}
\hline & & Chinese-American & South-Asian British & Black-American & Tobago & South-African & Mexican-American \\
\hline \multirow[t]{5}{*}{ Women } & Body weight & $\downarrow$ & $\uparrow$ & $\uparrow$ & $\uparrow$ & $=$ & $=$ \\
\hline & Height & $\downarrow$ & $\downarrow$ & $=$ & $\uparrow$ & $\downarrow$ & $\downarrow$ \\
\hline & $\mathrm{BMI}$ & $\downarrow$ & $\uparrow$ & $\uparrow$ & $\uparrow$ & $\uparrow$ & $\uparrow$ \\
\hline & Fat mass & $\downarrow$ & $\uparrow$ & $\uparrow$ & & & $\uparrow$ \\
\hline & Muscle mass & $\downarrow$ & $\downarrow$ & $\uparrow$ & & & $\downarrow$ \\
\hline \multirow[t]{5}{*}{ Men } & Body weight & $\downarrow^{\mathrm{a}}$ & $\downarrow$ & $=$ & $=$ & $\downarrow$ & $\downarrow$ \\
\hline & Height & $\downarrow^{a}$ & $\downarrow$ & $=$ & $=$ & $\downarrow$ & $\downarrow$ \\
\hline & $\mathrm{BMI}$ & $={ }^{a}$ & $=$ & $=$ & $\downarrow$ & $\downarrow$ & $=$ \\
\hline & Fat mass & $\uparrow^{a}$ & $\uparrow^{b}$ & $\downarrow$ & $\downarrow$ & & $\downarrow$ \\
\hline & Muscle mass & & $\downarrow^{b}$ & $\uparrow$ & & & \\
\hline Reference & & $(23,50)$ & $(32,34,51,52)$ & $(40,53)$ & $(45,54,55)$ & $(56,57)$ & $(40,58)$ \\
\hline
\end{tabular}

All parameters are compared to White individuals.

${ }^{a}$ Chinese ancestral origins living in China.

${ }^{b}$ South-Asian ancestral origins living in New Zealand.

which should be considered when studying differences in bone between and within different ethnic groups (38). For example, Chinese-American and Gambian women have a low BMI, which is a risk factor for fracture (Table 2) $(2,24)$. In postmenopausal women, a higher body weight is considered to be protective against fracture due to increased load (from greater muscle and fat mass) on the skeleton and also with fat accumulation providing padding during a fall (39). This is indicated in Black-American women who have greater fat and lean mass and aBMD, and lower fracture risk, compared to White-American women (40) (Table 2). A recent meta-analysis reported that muscle mass exerts a greater positive influence on aBMD than fat mass in men and women combined (41). However, increased weight appears to provide only partial protection, with an audit of fracture cases in UK and results from the Global Longitudinal Study of Osteoporosis in Women showing that obesity was a risk factor for fracture $(42,43)$. Those who fractured did not have a low aBMD (43), indicating the insensitivity of aBMD to predict fracture.

The NORA and SWAN studies $(2,44)$ emphasized the importance of taking into account body weight when quantifying differences in aBMD between Asian-American (Chinese and Japanese) and White-American women. Correcting for body weight decreased or reversed the differences in the total hip or spine aBMD between Asian-American (Chinese and Japanese) and White-American women $(2,44,45)$. Similarly, correcting for body size attenuated differences in aBMD at the hip, lumbar spine, and total body in South-Asian British (Pakistani and Gujarati) women compared to White-British women $(22,46)$.

There is a gap in the literature regarding the differences in body composition between men of different ethnicities (Table 2). The studies mentioned in Table 2 demonstrate that there are differences in muscle mass between ethnic groups. These studies also show that it is important to interpret aBMD from DXA with caution if bone area, height, and weight (or its component parts) are not adequately accounted for, as it may lead to misinterpretation of results (46).

\section{ETHNIC DIFFERENCES IN THE MUSCLE-BONE RELATIONSHIP}

Muscle strength is a composite term that describes muscle mass and anatomy (including intramuscular fat accumulation), force generating capacity and power (33). Muscle contractions are considered as the primary source of load upon the skeleton, more so than body weight, even in weight bearing bones (47). Given the differences in lean mass discussed in the previous section, it is likely that muscle force and power will also be different between ethnic groups, which are likely to contribute to differences in vBMD, size, shape, and distribution of bone. Measurements of muscle mass or cross-sectional area incompletely represent changes in muscle strength (48). Techniques to quantify the functional aspects of muscle strength include grip force, jumping mechanography, dynamometry, and electromyography. These dynamic tests give more accurate estimations of muscle strength than using muscle mass alone (46). Preliminary data from the EMAS demonstrated ethnic differences in the relationship between muscle force and power and age $(20,49)$.

There is a gap in the literature, because no studies published to date have investigated the relationships of muscle mass and function with vBMD, bone size and shape, and/or microarchitecture between ethnic populations. Differences in muscle force and power may partly underlie the ethnic differences in fracture incidence.

\section{CONCLUSION}

Fracture incidence varies between ethnic groups. Despite its many advantages, it is now recognized that the variance in fracture rates between ethnic groups cannot solely be explained by DXA. The studies described in this review highlights that "one size does not fit all" and there is a need to understand differences in skeletal phenotype at different stages of life (e.g., pre- versus postmenopausal) and in different populations both within and across continents (33). The separate measurement of cortical and trabecular bone compartments, and bone shape, size, microarchitecture, and metabolism is important to fully understand the differences of bone strength between ethnic groups. This requires technologies that move beyond measurements aBMD/BMC by DXA and use of 
three-dimensional imaging devices like pQCT and HRpQCT. The investigation of muscle and bone relationships in ethnic groups is also critical to the development of more effective strategies to improve musculoskeletal health and function. Future studies are required to identify how differences in nutrition, cultural preferences, socioeconomic factors, sunshine exposure, and physical activity levels affect bone health between ethnic groups.

\section{ACKNOWLEDGMENTS}

This research is funded by the Medical Research Council (MRC) (program codes U105960371, U123261351) and the Department for International Development (DFID) under the MRC/DFID Concordat agreement.

\section{REFERENCES}

1. Marshall D, Johnell O, Wedel H. Meta-analysis of how well measures of bone mineral density predict occurrence of osteoporotic fractures. BMJ (1996) 312:1254-9. doi:10.1136/bmj.312.7041.1254

2. Barrett-Connor E, Siris ES, Wehren LE, Miller PD, Abbott TA, Berger ML, et al. Osteoporosis and fracture risk in women of different ethnic groups. J Bone Miner Res (2005) 20:185-94. doi:10.1359/JBMR.041007

3. Bouxsein ML. Bone structure and fracture risk: do they go arm in arm? J Bone Miner Res (2011) 26:1389-91. doi:10.1002/jbmr.442

4. Ballane G, Cauley JA, Luckey MM, Fuleihan Gel H. Secular trends in hip fractures worldwide: opposing trends East versus West. J Bone Miner Res (2014) 29:1745-55. doi:10.1002/jbmr.2218

5. Cauley JA, Chalhoub D, Kassem AM, Fuleihan Gel H. Geographic and ethnic disparities in osteoporotic fractures. Nat Rev Endocrinol (2014) 10:338-51. doi:10.1038/nrendo.2014.51nrendo.2014.51

6. Kanis JA, Oden A, McCloskey EV, Johansson H, Wahl DA, Cooper C. A systematic review of hip fracture incidence and probability of fracture worldwide. Osteoporos Int (2012) 23:2239-56. doi:10.1007/s00198-012-1964-3

7. Prentice A. Diet, nutrition and the prevention of osteoporosis. Public Health Nutr (2004) 7:227-43. doi:10.1079/PHN2003590

8. Prentice A, Ward KA, Schoenmakers I, Goldberg GR, editors. Bone Growth in African Children and Adolescents. Boca Raton, FL: Taylor \& Francis Group (2012).

9. Solomon L. Osteoporosis and fracture of the femoral neck in the South African Bantu. J Bone Joint Surg Br (1968) 50:2-13.

10. Zebaze RM, Seeman E. Epidemiology of hip and wrist fractures in Cameroon, Africa. Osteoporos Int (2003) 14:301-5. doi:10.1007/s00198-002-1356- 1

11. Cooper C, Campion G, Melton LJ III. Hip fractures in the elderly: a world-wide projection. Osteoporos Int (1992) 2:285-9. doi:10.1007/BF01623184

12. Tsang SW, Kung AW, Kanis JA, Johansson H, Oden A. Ten-year fracture probability in Hong Kong Southern Chinese according to age and BMD femoral neck T-scores. Osteoporos Int (2009) 20:1939-45. doi:10.1007/s00198-009-0906- 1

13. Orimo H, Yaegashi Y, Onoda T, Fukushima Y, Hosoi T, Sakata K. Hip fracture incidence in Japan: estimates of new patients in 2007 and 20-year trends. Arch Osteoporos (2009) 4:71-7. doi:10.1007/s11657-009-0031-y

14. Lau EM, Lee JK, Suriwongpaisal P, Saw SM, Das De S, Khir A, et al. The incidence of hip fracture in four Asian countries: the Asian Osteoporosis Study (AOS). Osteoporos Int (2001) 12:239-43. doi:10.1007/s001980170135

15. Yan L, Zhou B, Prentice A, Wang X, Golden MH. Epidemiological study of hip fracture in Shenyang, People's Republic of China. Bone (1999) 24:151-5. doi:10.1016/S8756-3282(98)00168-9

16. Looker AC, Wahner HW, Dunn WL, Calvo MS, Harris TB, Heyse SP, et al. Updated data on proximal femur bone mineral levels of US adults. Osteoporos Int (1998) 8:468-89. doi:10.1007/s001980050093

17. Shin MH, Zmuda JM, Barrett-Connor E, Sheu Y, Patrick AL, Leung PC, et al. Race/ethnic differences in associations between bone mineral density and fracture history in older men. Osteoporos Int (2014) 25:837-45. doi:10.1007/s00198013-2503-6

18. Marshall LM, Zmuda JM, Chan BK, Barrett-Connor E, Cauley JA, Ensrud KE, et al. Race and ethnic variation in proximal femur structure and BMD among older men. J Bone Miner Res (2008) 23:121-30. doi:10.1359/jbmr.070908
19. Pye S, Ward K, Adams J, Finn J, Wu F, O’Neill T. Influence of ethnicity on bone mineral density and HIP axis length in UK men. In: Society BR, editor. Bone Research Society/British Orthopaedic Research Society - Joint Meeting. Oxford: Frontiers Media SA (2013). 96 p.

20. Ward K, Jeffery M, Pye S, Adams J, Boonen S, Vanderschueren D, et al. Abstracts of the osteoporosis conference 2010. November 28-December 1,2010. Liverpool, United Kingdom. Osteoporos Int (2010) 21:S443-518. doi:10.1007/s00198-0101388-x

21. Mehta G, Taylor P, Petley G, Dennison EM, Cooper C, Walker-Bone K. Bone mineral status in imigrant Indo-Asian women. Q J Med (2004) 97:97-9. doi:10.1093/qjmed/hch017

22. Roy D, Swarbrick C, King Y, Pye S, Adams J, Berry J, et al. Differences in peak bone mass in women of European and South Asian origin can be explained by differences in body size. Osteoporos Int (2005) 16:1254-62. doi:10.1007/s00198005-1837-0

23. Yan L, Crabtree NJ, Reeve J, Zhou B, Dequeker J, Nijs J, et al. Does hip strength analysis explain the lower incidence of hip fracture in the People's Republic of China? Bone (2004) 34:584-8. doi:10.1016/j.bone.2003.12.005

24. Aspray TJ, Prentice A, Cole TJ, Sawo Y, Reeve J, Francis RM. Low bone mineral content is common but osteoporotic fractures are rare in elderly rural Gambian women. J Bone Miner Res (1996) 11:1019-25. doi:10.1002/jbmr.5650110720

25. Aspray TJ, Prentice A, Cole TJ. The bone mineral content of weight-bearing bones is influenced by the ratio of sitting to standing height in elderly Gambian women. Bone (1995) 17:261-3. doi:10.1016/8756-3282(95)98407-E

26. Schnitzler CM, Pettifor JM, Mesquita JM, Bird MD, Schnaid E, Smyth AE. Histomorphometry of iliac crest bone in 346 normal black and white South African adults. Bone Miner (1990) 10:183-99. doi:10.1016/0169-6009(90)90261-D

27. Danielson ME, Beck TJ, Lian Y, Karlamangla AS, Greendale GA, Ruppert K, et al. Ethnic variability in bone geometry as assessed by hip structure analysis: findings from the hip strength across the menopausal transition study. J Bone Miner Res (2013) 28:771-9. doi:10.1002/jbmr.1781

28. Dibba B, Prentice A, Laskey MA, Stirling DM, Cole TJ. An investigation of ethnic differences in bone mineral, hip axis length, calcium metabolism and bone turnover between West African and Caucasian adults living in the United Kingdom. Ann Hum Biol (1999) 26:229-42. doi:10.1080/030144699282732

29. Prentice A, Shaw J, Laskey MA, Cole TJ, Fraser DR. Bone mineral content of British and rural Gambian women aged 18-80+ years. Bone Miner (1991) 12:201-14. doi:10.1016/0169-6009(91)90033-V

30. Wang Q, Teo JW, Ghasem-Zadeh A, Seeman E. Women and men with hip fractures have a longer femoral neck moment arm and greater impact load in a sideways fall. Osteoporos Int (2009) 20:1151-6. doi:10.1007/s00198-008-0768-y

31. Duboeuf F, Hans D, Schott AM, Kotzki PO, Favier F, Marcelli C, et al. Different morphometric and densitometric parameters predict cervical and trochanteric hip fracture: the EPIDOS Study. J Bone Miner Res (1997) 12:1895-902. doi:10.1359/jbmr.1997.12.11.1895

32. Ward KA, Roy DK, Pye SR, O’Neill TW, Berry JL, Swarbrick CM, et al. Forearm bone geometry and mineral content in UK women of European and South-Asian origin. Bone (2007) 41:117-21. doi:10.1016/j.bone.2007.03.013

33. Ward K. Musculoskeletal phenotype through the life course: the role of nutrition. Proc Nutr Soc (2012) 71:27-37. doi:10.1017/S0029665111003375

34. Darling AL, Hakim OA, Horton K, Gibbs MA, Cui L, Berry JL, et al. Adaptations in tibial cortical thickness and total volumetric bone density in postmenopausal South Asian women with small bone size. Bone (2013) 55:36-43. doi:10.1016/j.bone.2013.03.006

35. Liu XS, Walker MD, McMahon DJ, Udesky J, Liu G, Bilezikian JP, et al. Better skeletal microstructure confers greater mechanical advantages in ChineseAmerican women versus white women. J Bone Miner Res (2011) 26:1783-92. doi:10.1002/jbmr.378

36. Walker MD, Liu XS, Stein E, Zhou B, Bezati E, McMahon DJ, et al. Differences in bone microarchitecture between postmenopausal Chinese-American and white women. J Bone Miner Res (2011) 26:1392-8. doi:10.1002/jbmr.352

37. Putman MS, Yu EW, Lee H, Neer RM, Schindler E, Taylor AP, et al. Differences in skeletal microarchitecture and strength in African-American and white women. J Bone Miner Res (2013) 28:2177-85. doi:10.1002/jbmr.1953

38. Baker JF, Davis M, Alexander R, Zemel BS, Mostoufi-Moab S, Shults J, et al. Associations between body composition and bone density and structure in men and women across the adult age spectrum. Bone (2013) 53:34-41. doi:10.1016/j.bone.2012.11.035 
39. De Laet C, Kanis JA, Oden A, Johanson H, Johnell O, Delmas P, et al. Body mass index as a predictor of fracture risk: a meta-analysis. Osteoporos Int (2005) 16:1330-8. doi:10.1007/s00198-005-1863-y

40. Nelson DA, Beck TJ, Wu G, Lewis CE, Bassford T, Cauley JA, et al. Ethnic differences in femur geometry in the women's health initiative observational study. Osteoporos Int (2011) 22:1377-88. doi:10.1007/s00198-010-1349-4

41. Ho-Pham LT, Nguyen UD, Nguyen TV. Association between lean mass, fat mass, and bone mineral density: a meta-analysis. J Clin Endocrinol Metab (2014) 99:30-8. doi:10.1210/jc.2013-3190

42. Compston JE, Watts NB, Chapurlat R, Cooper C, Boonen S, Greenspan S, et al. Obesity is not protective against fracture in postmenopausal women: GLOW. Am J Med (2011) 124:1043-50. doi:10.1016/j.amjmed.2011.06.013

43. Premaor MO, Pilbrow L, Tonkin C, Parker RA, Compston J. Obesity and fractures in postmenopausal women. J Bone Miner Res (2010) 25:292-7. doi:10.1359/jbmr.091004

44. Finkelstein JS, Lee ML, Sowers M, Ettinger B, Neer RM, Kelsey JL, et al. Ethnic variation in bone density in premenopausal and early perimenopausal women: effects of anthropometric and lifestyle factors. J Clin Endocrinol Metab (2002) 87:3057-67. doi:10.1210/jcem.87.7.8654

45. Nam HS, Kweon SS, Choi JS, Zmuda JM, Leung PC, Lui LY, et al. Racial/ethnic differences in bone mineral density among older women. J Bone Miner Metab (2013) 31:190-8. doi:10.1007/s00774-012-0402-0

46. Prentice A, Parsons T, Cole T. Uncritical use of bone mineral density in absorptiometry may lead to size-related artifacts in the identification of bone mineral determinants. Am J Clin Nutr (1994) 60:837-42.

47. Frost H. Bone "mass" and the "mechanostat": a proposal. Anat Rec (1987) 219:1-9. doi:10.1002/ar.1092190104

48. Rittweger J, Schiessl H, Felsenberg D, Runge M. Reproducibility of the jumping mechanography as a test of mechanical power output in physically competent adult and elderly subjects. J Am Geriatr Soc (2004) 52:128-31. doi:10.1111/j. 1532-5415.2004.52022.x

49. Jeffrey M. Age-related change and ethnic differences in neuromuscular function. 8th International Workshop For Musculoskeletal \& Neuronal Interactions. Ipswich (2012).

50. Khan UI, Wang D, Sowers MR, Mancuso P, Everson-Rose SA, Scherer PE, et al. Race-ethnic differences in adipokine levels: the study of women's health across the nation (SWAN). Metabolism (2012) 61:1261-9. doi:10.1016/j.metabol.2012. 02.005

51. McKeigue PM, Pierpoint T, Ferrie JE, Marmot MG. Relationship of glucose intolerance and hyperinsulinaemia to body fat pattern in south Asians and Europeans. Diabetologia (1992) 35:785-91.
52. Rush EC, Freitas I, Plank LD. Body size, body composition and fat distribution: comparative analysis of European, Maori, Pacific Island and Asian Indian adults. Br J Nutr (2009) 102:632-41. doi:10.1017/S0007114508207221

53. Taaffe DR, Cauley JA, Danielson M, Nevitt MC, Lang TF, Bauer DC, et al. Race and sex effects on the association between muscle strength, soft tissue, and bone mineral density in healthy elders: the health, aging, and body composition study. J Bone Miner Res (2001) 16:1343-52. doi:10.1359/jbmr.2001.16.7.1343

54. Miljkovic I, Cauley JA, Petit MA, Ensrud KE, Strotmeyer E, Sheu Y, et al. Greater adipose tissue infiltration in skeletal muscle among older men of African ancestry. J Clin Endocrinol Metab (2009) 94:2735-42. doi:10.1210/jc.2008-2541

55. Nam HS, Shin MH, Zmuda JM, Leung PC, Barrett-Connor E, Orwoll ES, et al. Race/ethnic differences in bone mineral densities in older men. Osteoporos Int (2010) 21:2115-23. doi:10.1007/s00198-010-1188-3

56. Chantler S, Dickie K, Goedecke JH, Levitt NS, Lambert EV, Evans J, et al. Sitespecific differences in bone mineral density in black and white premenopausal South African women. Osteoporos Int (2012) 23:533-42. doi:10.1007/s00198011-1570-9

57. Malan NT, Hamer M, Schutte AE, Huisman HW, Van Rooyen JM, Schutte R, et al. Low testosterone and hyperkinetic blood pressure responses in a cohort of South African men: the SABPA study. Clin Exp Hypertens (2013) 35:228-35. doi:10.3109/10641963.2012.721839

58. Heo M, Faith MS, Pietrobelli A, Heymsfield SB. Percentage of body fat cutoffs by sex, age, and race-ethnicity in the US adult population from NHANES 1999-2004. Am J Clin Nutr (2012) 95:594-602. doi:10.3945/ajcn.111.025171

Conflict of Interest Statement: The authors declare that the research was conducted in the absence of any commercial or financial relationships that could be construed as a potential conflict of interest.

Received: 29 January 2015; paper pending published: 08 February 2015; accepted: 10 February 2015; published online: 17 March 2015.

Citation: Zengin A, Prentice A and Ward KA (2015) Ethnic differences in bone health. Front. Endocrinol. 6:24. doi: 10.3389/fendo.2015.00024

This article was submitted to Bone Research, a section of the journal Frontiers in Endocrinology.

Copyright ( 2015 Zengin, Prentice and Ward. This is an open-access article distributed under the terms of the Creative Commons Attribution License (CC BY). The use, distribution or reproduction in other forums is permitted, provided the original author(s) or licensor are credited and that the original publication in this journal is cited, in accordance with accepted academic practice. No use, distribution or reproduction is permitted which does not comply with these terms. 